Ann. Zootech., I97I, 20 (2), 247-250.

NOTE

\title{
UTILISATION DIGESTIVE DES MATIÈRES GRASSES PAR LE VEAU PRÉRUMINANT A L'ENGRAIS : INFLUENCE DU TAUX D'INCORPORATION DANS LES ALIMENTS D'ALLAITEMENT
}

\author{
R. TOULLEC (1) et C.-M. MATHIEU (1) \\ Station de Recherches sur l'Élevage des Ruminants, \\ Centre de Recherches de Clermont-Ferrand, I. N. R. A., \\ 63 - Saint-Genès-Champanelle
}

Les aliments d'allaitement pour veaux contiennent généralement moins de matières grasses ( 5 à 25 p. I00) que le lait entier ( 25 à 30 p. Ioo de la matière sèche). De plus, les aliments les plus riches ne sont généralement distribués qu'en fin d'engraissement. MathIEU et BarRÉ (I964), en comparant l'utilisation digestive par le veau de laits entiers et plus ou moins écrémés contenant I $5,25,35$ ou 45 p. I ooo de matières grasses $\left(1_{4}, 22,27\right.$ ou 32 p. Ioo de la matière sèche), n'ont constaté de diminution de la digestibilité que pour le taux le plus élevé ; cette diminution était associée à une plus grande fréquence des diarrhées. Il nous a donc paru intéressant de voir s'il y avait des limites digestives à l'utilisation des matières grasses de remplacement qui sont généralement très différentes de celles du lait. Nous avons mesuré l'utilisation digestive par le veau préruminant, de deux aliments d'allaitement contenant respectivement 27 et 32 p. Ioo de suif (aliment 27 et aliment 32), matière grasse la plus classiquement utilisée en France.

Les deux aliments d'allaitement ont été préparés en deux étapes : dans un premier temps, un mélange de lait écrémé liquide et de suif fondu (35 p. Ioo de la matière sèche) a été homogénéisé puis déshydraté dans une tour Spray; dans un deuxième temps, la composition recherchée pour chaque aliment d'allaitement a été obtenue en mélangeant cette poudre de lait ainsi enrichie en matières grasses à de la poudre de lait écrémé; un mélange minéral et vitaminique contenant également de la chlortétracycline et de la furazolidone a été ajouté au cours de la même opération. Ces aliments contenaient respectivement (en $p$. Ioo de la matière sèche) : $27, \mathrm{r}$ et $3 \mathrm{I}, 7$ de matières grasses, 25,3 et 21,7 de matières azotées et 6,4 et 5,8 de matières minérales.

Chacun des aliments a été distribué à 3 veaux mâles (2 Frisons et I Montbéliard $\times$ Frison) sur lesquels on a mesuré la digestibilité de la matière sèche entre les âges d'environ $\mathbf{5} 5$ et 96 jours ; cependant, seules les fèces des 2 veaux qui ont eu le meilleur appétit ont été analysées. Les mesures ont été effectuées en 6 périodes de I I jours séparées par des interpériodes de 3 jours. Les aliments

(1) Adresse actuelle : Laboratoire de Recherches de la Chaire de Zootechnie, Centre de Recherches de Rennes, 65, rue de Saint-Brieuc, 35 - Rennes. 
d'allaitement ont été dilués dans de l'eau à $4^{\circ} \mathrm{C}$ et les laits ainsi obtenus ont été distribués au seau deux fois par jour. La concentration qui était de $\mathrm{r} z \mathrm{~g} \mathrm{~g}$ par $\mathrm{kg}$ de lait au cours de la $\mathrm{I}^{\mathrm{re}}$ période, augmentait progressivement pour atteindre 160 à partir de la $5^{\mathrm{c}}$ période. Les quantités d'aliment d'allaitement distribuées par jour étaient importantes et augmentaient avec l'âge et le poids métabolique (poids vif ${ }^{\mathbf{0}, 75}$ ) : elles étaient de $55 \mathrm{~g}$ par $\mathbf{k g}$ de poids métabolique au cours des deux premières périodes, puis de $67 \mathrm{~g}$, passant ainsi progressivement d'un minimum de I $\mathrm{kg}$ par veau à un maximum de $2,7 \mathrm{~kg}$. Le dosage des matières grasses a été effectué dans les aliments selon la méthode de Folch, Lees et Sloane Stanley (I957) et dans les fèces par extraction chloroformique après hydrolyse chlorhydrique, l'extrait chloroformique étant dans ce dernier cas saponifié pour isoler les acides gras. Les autres méthodes de mesure et d'analyse ont été exposées en détail dans une publication précédente (Toullec Mathieu, 1969).

L'appétit, la croissance, l'efficacité alimentaire et l'état sanitaire ont été dans l'ensemble très satisfaisants. Les veaux qui recevaient l'aliment 32 ont cependant fait davantage de refus ( I I,6 p. Ioo au lieu de 5,7); en conséquence, ils n’ont consommé que 9,6 p. Ioo de matières grasses de plus que les animaux recevant l'aliment 27 , au lieu de $17,0 \mathrm{p}$. roo. Les veaux qui consommaient l'aliment 27 ont effectué la croissance la plus rapide ( $123 \mathrm{~g} / \mathrm{j}$ au lieu de I 045). Les animaux qui recevaient l'aliment 32 ont ingéré moins de matière sèche par $\mathrm{kg}$ de gain de poids (, $347 \mathrm{~kg}$ au lieu de $I, 4$ Io) mais ils ont consommé la même quantité d'énergie brute (calculée). L'état d'engraissement a été en général satisfaisant et n'a pas été systématiquement influencé par le régime : en effet, la somme des dépôts adipeux périrénaux, péritonéaux et intestinaux a constitué dans les deux cas 2,4 p. Ioo du poids vif vide. La fréquence des jours de diarrhées (jour où la teneur en matière sèche des fèces a été inféricure à $\mathbf{2} 2$ p. Ioo) a été sensiblement la même dans les 2 cas : respectivement I3,6 et 9,7 p. Ioo chez les veaux qui consommaient l'aliment 27 et ceux qui recevaient l'aliment 32 .

\section{TABLEAU I}

\begin{tabular}{|c|c|c|c|c|c|c|c|c|}
\hline \multirow{2}{*}{$\begin{array}{c}\text { Teneur en } \\
\text { matières } \\
\text { grasses de } \\
\text { l'aliment } \\
\text { d'allaitement } \\
\text { (p.100 dela MS) }\end{array}$} & \multirow[b]{2}{*}{$\begin{array}{l}\text { Numéro } \\
\text { du veau }\end{array}$} & \multirow{2}{*}{$\begin{array}{c}\text { Gain de } \\
\text { poids } \\
(\mathrm{g} / \mathrm{j})\end{array}$} & \multirow{2}{*}{$\begin{array}{c}\text { MS } \\
\text { totale } \\
\text { consom } \\
\text { mée } \\
(\mathrm{kg})\end{array}$} & \multicolumn{4}{|c|}{ CUD apparent (p. 100) } & \multirow{2}{*}{$\begin{array}{c}\text { CR } \\
\text { apparent } \\
\text { de l'azote } \\
\text { (p. 100) }\end{array}$} \\
\hline & & & & $\begin{array}{l}\text { Matière } \\
\text { sèche }\end{array}$ & $\begin{array}{c}\text { Matière } \\
\text { organique }\end{array}$ & $\begin{array}{l}\text { Matières } \\
\text { grasses }\end{array}$ & Azote & \\
\hline 27 & $\begin{array}{l}69778^{*} \\
69213^{* *}\end{array}$ & $\begin{array}{l}1284 \\
1222\end{array}$ & $\begin{array}{l}135,3 \\
134,4\end{array}$ & $\begin{array}{l}96,8 \pm 0,8 \\
95,4 \pm 1,8\end{array}$ & $\left|\begin{array}{l}97,0 \pm 0,7 \\
95,8 \pm 1,6\end{array}\right|$ & $\begin{array}{l}94,4 \text { 土 } 1,7 \\
91,2 \pm 3,9\end{array}$ & $\left|\begin{array}{l}95,8 \pm 0,6 \\
94,3 \pm 2,2\end{array}\right|$ & $\begin{array}{l}74, \geq \pm \quad 4,8 \\
74,4 \pm \quad 5,8\end{array}$ \\
\hline 32 & $\begin{array}{l}69780^{*} \\
69215^{* *}\end{array}$ & $\begin{array}{ll}1 & 198 \\
1 & 0 \\
4\end{array}$ & $\begin{array}{l}117,9 \\
116,3\end{array}$ & $\left|\begin{array}{l}97,3 \pm 0,9 \\
95,6 \pm 1,8\end{array}\right|$ & $\left|\begin{array}{l}97,4 \pm 0,8 \\
95,9 \pm 1,6\end{array}\right|$ & $\begin{array}{l}95,5 \pm 1,8 \\
91,9 \pm 3,9\end{array}$ & $\left|\begin{array}{l}95,9 \pm 0,8 \\
9,3 \pm 1,6\end{array}\right|$ & $\begin{array}{l}79,3 \pm 4,4 \\
70,6 \pm 10,9\end{array}$ \\
\hline
\end{tabular}

* Veaux Frisons.

** Veaux Montbéliards $\times$ Frisons.

La digestibilité apparente (tabl. I) des deux aliments d'allaitement a été élevée (95,6 p. Ioo pour la matière sèche). Ses variations avec l'âge ont surtout porté sur les matières grasses (fig. I) et les matières minérales. Les différences entre régimes ont été très faibles (tabl. I) : ainsi, la digestibilité des matières grasses a été de 92,8 p. roo pour l'aliment 27 et de 93,7 p. 100 pour l'aliment 32 . La digestibilité des matières grasses a même été plus élevée que celle (90 p. Ioo) que nous avions obtenue dans un essai précédent (Toullec et Mathieu, I969) pour un suif incorporé à raison de 20 p. Ioo de la matière sèche; cela est probablement dû aux différences dans la composition en 
acides gras (dans l'essai précédent, le suif contenait 27 p. Ioo d'acide stéarique et dans cet essai I 8 p. roo). Roy et al. (I970) n'ont pas non plus observé de différence dans la digestibilité des matières grasses entre deux aliments d'allaitement contenant respectivement $2 \mathrm{I}$ et $29 \mathrm{p}$. Ioo de matières grasses, mais celles-ci contenaient des proportions notables d'acides gras courts et moyens et seulement 4,5 p. Ioo d'acide stéarique. Chez les veaux croisés, l'utilisation digestive a été plus faible que chez les deux animaux de race pure qui ont ingéré les mêmes quantités d'aliments (respectivement 9I,5 et 94,9 pour les matières grasses; $P \leqslant 0,02$ ) ; ceci demanderait cependant à être confirmé sur un plus grand nombre d'animaux. Roy, Stobo et Gaston (I97o) ont de même signalé que l'utilisation digestive des aliments d'allaitement était plus élevée chez les veaux de race Frisonne que chez ceux de race Ayrshive. L'utilisation de l'azote a été très élevée pour chacun des veaux, indépendamment du régime (CR apparents compris entre 7o,6 et 79,3 p. Ioo). Le CR apparent le moins élevé a été observé chez l'animal dont la croissance a été la moins rapide. Le CR apparent de l'azote a varié avec l'âge mais différemment suivant le régime (fig. I). Les veaux qui recevaient l'aliment 27 ont apparemment retenu davantage d'azote par kg de gain de poids $(37,3 \mathrm{~g}$ au lieu de 29,4$)$.

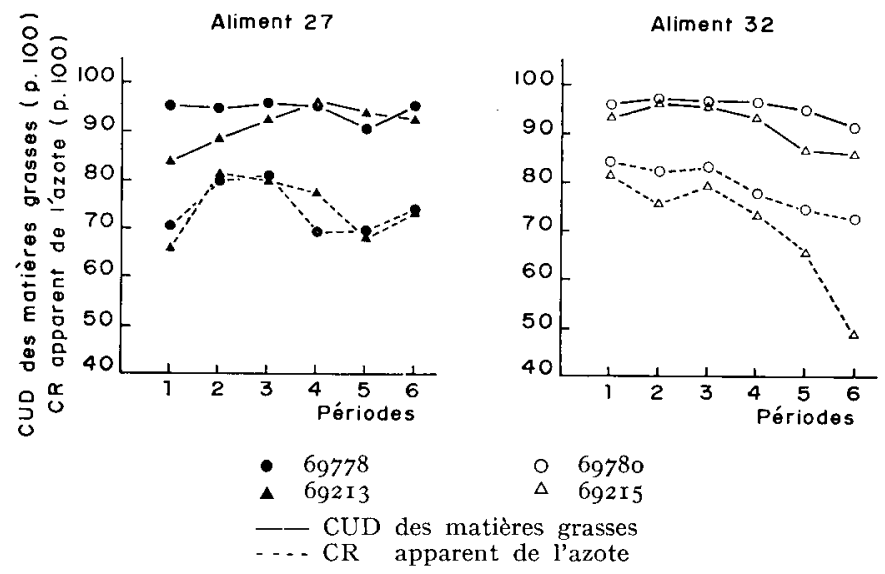

FIG. x. - Évolution de la digestibilite des matières grasses et de la rétention azotée avec l'âge

En conclusion, les matières grasses de remplacement, comme le suif, ont une utilisation digestive élevée même lorsqu'elles sont introduites à des taux très importants dans les aliments d'allaitement, au moins quand la technologie de l'incorporation est satisfaisante. Ce n'est donc pas au niveau digestif que se situent les limites à l'utilisation des matières grasses par le veau préruminant, mais plutôt au niveau métabolique (effet dépressif sur l'appétit et la croissance).

Reçu pour publication en janvier 1971.

\section{SUMMARY}

\section{DIGESTIVE UTILIZATION OF FAT BY THE PRERUMINANT FATTENING CALF : EFFECT OF THE LEVEI, OF INCORPORATION IN THE MILK SUBSTITUTES}

Two milk substitutes containing $27, \mathrm{I}$ and $3 \mathrm{I}, 7 \mathrm{p}$. Ioo respectively (compared with the dry matter) of tallow, incorporated in liquid skim milk by means of homogenisation, were each distributed to three preruminant calves. The digestibility measurements were performed between the ages of about 15 and 96 days. 
The apparent digestibility of the fat (table $\mathrm{r}$ ) was very high $(92,8 \mathrm{p}$. I oo for feed 27 and $93,7 \mathrm{p}$. I oo for feed 32), and even superior to that obtained in a previous trial where the tallow only constituted $20 \mathrm{p}$. 100 of the milk substitute. Thus, the digestive utilization of fat substitutes like tallow is high even when incorporated in the milk substitutes at very important levels.

\section{RÉFÉRENCES BIBLIOGRAPHIQUES}

Folch J., Lees M., Sloane Stanley G. H., I957. A simple method for the isolation and purification of total lipids from animal tissues. J. Biol. Chem., 226, 497-509.

Mathieu C.-M., BarRé P.-E., I964. Digestion et utilisation des aliments par le veau préruminant à l'engrais. I. Utilisation des laits entiers ou partiellement écrémés. Ann. Biol. anim. Bioch. Biophys., 4, 403-422.

Roy J. H. B., Stobo I. J. F., Gaston Heien J., Greatorex J. C., I97o. The nutrition of the veal calf. II. The effect of different levels of protein and fat in milk substitute diets. Brit. J. Nutr., 24, $44 \mathrm{I}-457$.

Roy J. H. B., Stoвo I. J. F., Gaston Helen J., r97o. The nutrition of the veal calf. III. A comparison of liquid skim-milk with a diet of reconstituted spray dried skim-milk powder containing 20 p. roo margarine fat. Brit. J. Nutr., 24, 459-475.

Toullec R., Mathieu C.-M., I969. Utilisation digestive des matières grasses et de leurs principaux acides gras par le veau préruminant à l'engrais. Influence sur la composition corporelle. Ann. Biol. anim. Bioch. Biophys,, 9, I39-г60. 